\title{
EFFECTS OF A SAW PALMETTO HERBAL BLEND IN MEN WITH SYMPTOMATIC BENIGN PROSTATIC HYPERPLASIA
}

\author{
LEONARD S. MARKS, ALAN W. PARTIN, JONATHAN I. EPSTEIN, VARRO E. TYLER,* \\ INPAKALA SIMON, MARIA L. MACAIRAN, THERESA L. CHAN, FREDERICK J. DOREY, \\ JOEL B. GARRIS, ROBERT W. VELTRI, PAUL BRYAN C. SANTOS, KERRY A. STONEBROOK* \\ AND JEAN B. DEKERNION
}

\begin{abstract}
From the Departments of Urology and Biostatistics, University of California Los Angeles School of Medicine, Los Angeles, Rehnborg Center for Nutrition and Wellness, Nutrilite Division of Amway Corp., Buena Park and Urological Sciences Research Foundation, and Radiology Department, Brotman Medical Center, Culver City, California, Department of Pathology, Brady Urological Institute, Johns Hopkins University School of Medicine, Baltimore, Maryland, Department of Medicinal Chemistry and Molecular Pharmacology, Purdue University, West Lafayette, Indiana, and Urocor, Inc., Oklahoma City, Oklahoma
\end{abstract}

\section{ABSTRACT}

Purpose: We tested the effects of a saw palmetto herbal blend in men with symptomatic benign prostatic hyperplasia $(\mathrm{BPH})$ via a randomized, placebo controlled trial.

Materials and Methods: We randomized 44 men 45 to 80 years old with symptomatic BPH into a trial of a saw palmetto herbal blend versus placebo. End points included routine clinical measures (symptom score, uroflowmetry and post-void residual urine volume), blood chemistry studies (prostate specific antigen, sex hormones and multiphasic analysis), prostate volumetrics by magnetic resonance imaging, and prostate biopsy for zonal tissue morphometry and semiquantitative histology studies.

Results: Saw palmetto herbal blend and placebo groups had improved clinical parameters with a slight advantage in the saw palmetto group (not statistically significant). Neither prostate specific antigen nor prostate volume changed from baseline. Prostate epithelial contraction was noted, especially in the transition zone, where percent epithelium decreased from $17.8 \%$ at baseline to $10.7 \%$ after 6 months of saw palmetto herbal blend $(p<0.01)$. Histological studies showed that the percent of atrophic glands increased from $25.2 \%$ to $40.9 \%$ after treatment with saw palmetto herbal blend $(\mathrm{p}<0.01)$. The mechanism of action appeared to be nonhormonal but it was not identified by tissue studies of apoptosis, cellular proliferation, angiogenesis, growth factors or androgen receptor expression. We noted no adverse effects of saw palmetto herbal blend. When the study was no longer blinded, 41 men elected to continue therapy in an open label extension.

Conclusions: Saw palmetto herbal blend appears to be a safe, highly desirable option for men with moderately symptomatic BPH. The secondary outcome measures of clinical effect in our study were only slightly better for saw palmetto herbal blend than placebo (not statistically significant). However, saw palmetto herbal blend therapy was associated with epithelial contraction, especially in the transition zone $(\mathrm{p}<0.01)$, indicating a possible mechanism of action underlying the clinical significance detected in other studies.

KEY WoRDS: prostate; prostatic hyperplasia; medicine, herbal

The saw palmetto plant or Serenoa repens (Bartr.) Small is a dwarf palm indigenous to the southeastern United States and West Indies. ${ }^{1}$ For many years saw palmetto extract has been used to treat symptomatic benign prostatic hyperplasia (BPH) throughout Europe. ${ }^{2,3}$ However, available information on saw palmetto extract consists largely of in vitro ex-

Accepted for publication November 12, 1999

Presented at annual meeting of the American Urological Association, Dallas, Texas, May 1-6, 1999.

Supported by an unrestricted educational grant from the Nutrilite Division of Amway Corp, Buena Park, California.

* Financial interest and/or other relationship with Nutrilite Division of Amway Corp.

Editor's Note: This article is the second of 5 published in this issue for which category 1 CME credits can be earned. Instructions for obtaining credits are given with the questions on pages 1540 and 1541. periments and European trials, of which many have limited value, as noted by Lowe et al. ${ }^{4,5}$ Thus, we performed a randomized, placebo controlled trial to evaluate the tissue and clinical effects (primary and secondary outcome measures, respectively) of a saw palmetto herbal blend in men with symptomatic $\mathrm{BPH}$.

\section{MATERIALS AND METHODS}

Included in our study were 44 ambulatory men 45 to 80 years old with symptomatic BPH but in good general health who were recruited from a pool of 160 eligible candidates treated at a general urology practice in metropolitan Los Angeles, California, between September 1997 and January 1998 (table 1). Appendix 1 shows study inclusion and exclusion criteria. All subjects signed a consent form approved by the Western Institutional Review Board, Seattle, Washington. Of the 44 randomized men 43 completed the study, 
TABLE 1. Patient characteristics at baseline

\begin{tabular}{lcc}
\hline & $\begin{array}{c}\text { Saw Palmetto } \\
\text { Herbal Blend }\end{array}$ & Placebo \\
\hline No. pts. & 21 & 23 \\
Mean age \pm SD & $65.1 \pm 8.1$ & $62.9 \pm 9.3$ \\
No. race: & 16 & 16 \\
$\quad$ White & 2 & 1 \\
Black & 1 & 4 \\
Asian & 2 & 2 \\
Hispanic or Latino & $18.1 \pm 7.2$ & $16.6 \pm 5.3$ \\
Mean I-PSS \pm SD & $10.3 \pm 4.3$ & $10.8 \pm 4.5$ \\
Mean max. urine flow \pm SD (cc/sec.) & $2.7 \pm 2.0$ & $4.1 \pm 3.5$ \\
Mean serum PSA \pm SD (ng./ml.) & $0.66 \pm 0.29$ & $0.60 \pm 0.46$ \\
Mean serum dihydrotestosterone \pm SD (ng./dl.) & & \\
Mean prostate vol. \pm SD (cc): & $58.5 \pm 29.8$ & $55.6 \pm 26.7$ \\
Whole organ & $32.2 \pm 29.0$ & $27.4 \pm 21.9$ \\
Inner organ & & \\
Mean \% transition zone composition \pm SD: & $17.3 \pm 11.2$ & $15.4 \pm 14.5$ \\
Epithelium & $20.3 \pm 12.8$ & $18.0 \pm 5.8$ \\
Lumen & $62.5 \pm 16.1$ & $66.6 \pm 14.5$ \\
Stroma & & \\
\hline
\end{tabular}

including 41 for whom complete data are available, while 1 died of myocardial infarction 4 months after randomization.

We performed a 6-month randomized, double-blind placebo controlled trial (fig. 1 and table 2). After the 6-month visit all patients were invited to enter a long-term open label trial extension. We used a similar study design 2 years earlier for evaluation of finasteride. ${ }^{6,7}$

A table of random numbers was used to assign subjects at a ratio of 1:1 to receive a sealed opaque bottle of soft gelatin capsules of a saw palmetto herbal blend or sealed opaque bottle of inert placebo capsules of glycerin, yellow wax, lecithin and a small quantity of soybean oil. To our subjects and us placebo was indistinguishable from the saw palmetto herbal blend capsule. Each preparation was ingested 3 times daily with meals. The herbal blend contained a standard preparation of $106 \mathrm{mg}$. of saw palmetto berry lipoidal extract and other herbs (table 3 ). We used a single product lot throughout the study. Average compliance, assessed by counting the remaining capsules at each visit, was $94.2 \%$ for all men during the trial. No subject had a compliance of less than $75 \%$ at any time.

Clinical outcomes included the International Prostate Symptom Score (I-PSS) and sexual function questionnaires, quality of life index, uroflowmetry, ultrasound of post-void residual urine volume, Tandem- $\mathrm{R} \dagger$ prostate specific antigen (PSA) blood test, and testosterone, dihydrotestosterone and estradiol measurements. A panel of 26 conventional blood tests was also performed to obtain evidence of adverse effects (Appendix 2). Prostate volume was determined by magnetic resonance imaging (MRI), which permitted the measurement of whole and inner prostate volume separately using the formula for an ellipsoid. Sextant biopsy of the prostate was performed according to the method of Hodge et al. ${ }^{8}$ Each biopsy core was stained with india ink at the deep end to identify the transition zone. Detailed methodology of these outcome measures has been reported previously. ${ }^{6}$

Prostate biopsy cores were fixed in formalin and embedded in paraffin. Sections $(5 \mu)$ were cut until tissue was exhausted, usually providing 15 to 20 slices. After routine histological study ruled out malignancy the remaining sections were preserved unstained for subsequent tissue analysis. After study completion all tissues were batch analyzed for evidence of atrophy, inflammation and neoplasia by hematoxylin and eosin staining by a single referee pathologist (J. I. E.), who remained blinded to clinical information. Atrophy and inflammation were estimated by $4 \times$ magnification assessment of the percent of atropic glands, and by scoring the overall core for the amount of acute and chronic inflammatory tissue. Estimates from all cores were then

$\dagger$ Hybritech Beckman-Coulter Corp., San Diego, California.

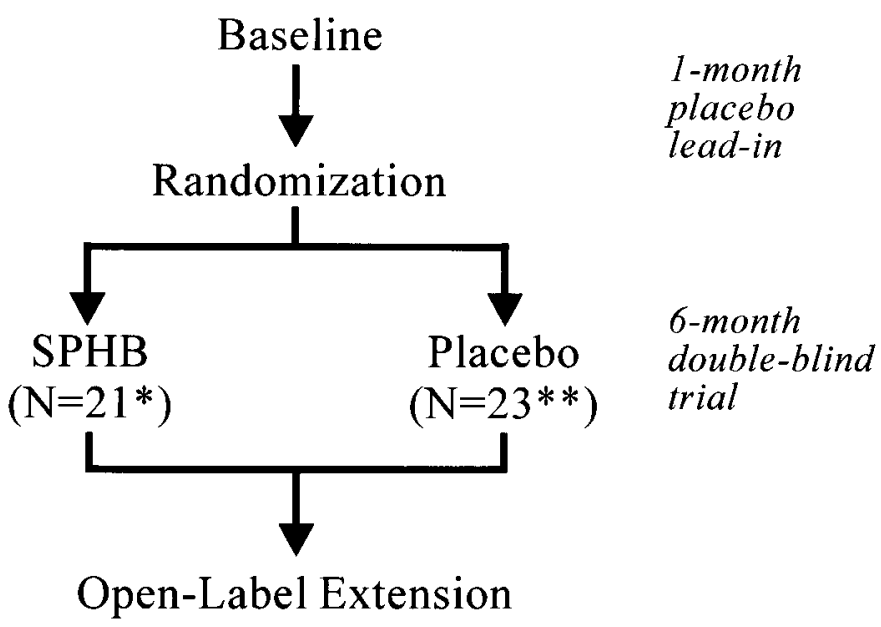

Fig. 1. Study design was patterned on typical Food and Drug Administration phase II randomized drug trial. Of 44 men who entered study 41 finished with complete data 6 months later. Asterisk indicates myocardial infarction during trial in 1 subject. Double asterisks indicate 2 subjects who refused followup biopsy. $S P H B$, saw palmetto herbal blend.

averaged. Prostate cores were also subjected to immunohistochemical staining and image analysis for quantitating tissue components (stroma, epithelium and lumen), ${ }^{6}$ apoptosis, ${ }^{9}$ cellular proliferation (Ki-67), ${ }^{9}$ angiogenesis (factor VIII), ${ }^{10}$ transforming growth factor- $\beta^{11}$ and androgen receptor expression. $^{12}$

All data were entered into a personal computer via spreadsheet software and analyzed using a commercially available statistical package. As in a former study, ${ }^{6}$ statistical methods included the paired and 2-sample Student t tests, Kendall's tau and linear regression with statistical significance considered at $\mathrm{p}<0.05$. Primary end points were the tissue changes that our study was designed and powered to detect. Clinical measures were secondary end points since previous analogous trials of finasteride showed that the study was not adequately powered to detect slight clinical changes. ${ }^{6,7}$

\section{RESULTS}

At baseline the study and placebo groups were similar in demographic and clinical characteristics (table 1). Of the 44 men 41 finished the study with complete data available, 1 in the saw palmetto group died suddenly of unrelated cardiac causes halfway through the trial and 2 in the placebo group refused followup biopsy but otherwise finished the study with all other data complete. When the study was no longer blinded at the end of 6 months, all 23 placebo treated men entered the open label saw palmetto herbal blend extension. Of the 21 men receiving saw palmetto herbal blend 18 also elected to enter the extension.

Table 4 shows the effects of intervention on symptom score, flow rate and post-void residual urine in the 2 groups. During the initial placebo lead-in month we noted a slight decrease in symptom score and increase in urinary flow in each group (not statistically significant). After randomization a slight progression of these trends continued. The ultimate change from baseline was slightly greater in the saw palmetto than in the placebo group (not statistically significant). No correlation was present between any of the clinical variables at baseline (table 1) and subsequent response to saw palmetto herbal blend.

Table 4 lists data on serum free-to-total PSA, testosterone, dihydrotestosterone and estradiol. Baseline serum levels of PSA were slightly higher in the placebo than in the saw palmetto herbal blend group (not significant). No statistically 
TABLE 2. Study flow chart

\begin{tabular}{|c|c|c|c|c|c|c|c|c|c|c|}
\hline \multirow{2}{*}{ Evaluation } & \multirow{2}{*}{$\begin{array}{l}\text { Baseline } \\
\text { Wk. } 4\end{array}$} & \multirow{2}{*}{$\begin{array}{l}\text { Randomization } \\
\text { Wk. } 0\end{array}$} & \multicolumn{8}{|c|}{ Treatment, Wk. } \\
\hline & & & 3 & 6 & 9 & 12 & 15 & 18 & 21 & 24 \\
\hline History + physical examination & $\mathrm{X}$ & & & & & & & & & $\mathrm{X}$ \\
\hline I-PSS, uroflowmetry + bladder scan & $\mathrm{X}$ & $\mathrm{X}$ & & $\mathrm{X}$ & & $\mathrm{X}$ & & $\mathrm{X}$ & & $\mathrm{X}$ \\
\hline Transrectal ultrasound + biopsy & $\mathrm{X}$ & & & & & & & & & $\mathrm{X}$ \\
\hline MRI & $\mathrm{X}$ & & & & & & & & & $\mathrm{X}$ \\
\hline $\begin{array}{l}\text { Complete blood count, } 25 \text { blood chemistry studies }+ \\
\text { urinalysis }\end{array}$ & $\mathrm{X}$ & & & & & $\mathrm{X}$ & & & & $\mathrm{X}$ \\
\hline $\begin{array}{l}\text { Free + total PSA, dehydrotestosterone, testosterone } \\
\quad+\text { estradiol }\end{array}$ & $\mathrm{X}$ & & & & & $\mathrm{X}$ & & & & $\mathrm{X}$ \\
\hline Treatment dispensed & $\mathrm{X}$ & $\mathrm{X}$ & & & & $\mathrm{X}$ & & & & \\
\hline Adverse event query & & $\mathrm{X}$ & $\mathrm{X}$ & $\mathrm{X}$ & $\mathrm{X}$ & $\mathrm{X}$ & $\mathrm{X}$ & $\mathrm{X}$ & $\mathrm{X}$ & $\mathrm{X}$ \\
\hline Telephone contact & & & $\mathrm{X}$ & & $\mathrm{X}$ & & $\mathrm{X}$ & & $\mathrm{X}$ & \\
\hline Capsule count (pt. compliance) & & $\mathrm{X}$ & & $\mathrm{X}$ & & $\mathrm{X}$ & & $\mathrm{X}$ & & $\mathrm{X}$ \\
\hline
\end{tabular}

TABLE 3. Saw palmetto extract/herbal blend soft gelatin capsule composition

\begin{tabular}{lc}
\hline \multicolumn{1}{c}{ Component } & Amount \\
\hline Saw palmetto lipoidal extract (mg.) & 106 \\
Nettle root extract (mg.) & 80 \\
Pumpkin seed oil extract (mg.) & 160 \\
Lemon bioflavonoid extract (mg.) & 33 \\
Vitamin A, 100\% as $\beta$-carotene (IU) & 190 \\
Other minor ingredients (gelatin, glycerin, yellow & \\
beeswax, soybean oil, lecithin, corn oil + natural & \\
$\quad$ caramel color) & \\
\hline Dose was 1 tablet 3 times daily with meals or 318 mg. saw palmetto extract \\
daily.
\end{tabular}

significant changes were noted in any of these measurements after saw palmetto herbal blend treatment. Table 4 also shows prostate volume at baseline and again after 6 months of randomization. No statistically significant volume change was apparent in the whole or inner prostate when measured separately.

In the saw palmetto group the atrophy index, defined as the percent of the prostate that was atrophic on $\times 4$ magnification inspection of the whole core, increased significantly after treatment from an average of $25.2 \%$ at baseline to $40.9 \% 6$ months later ( $p<0.01$, fig. 2). In placebo treated patients the atrophy index was $43.1 \%$ at baseline, increasing only slightly to $48.4 \%$ after 6 months (not statistically significant). Figure 3 represents a sample of epithelial involution after saw palmetto herbal blend. No change in inflammatory features was observed in either group after treatment (data not shown).

In the transition zone the percent epithelium decreased from a mean of $17.8 \%$ at baseline to $10.7 \%$ after 6 months of saw palmetto herbal blend therapy ( $p<0.01$, fig. 4). No significant change was noted in the stromal or luminal percent, or in any tissue component of the men treated with placebo. We detected a qualitatively similar change in peripheral zone epithelium before and after treatment but it was not statistically significant $(21.8 \%$ versus $17.7 \%)$. None of the other tissue studies, including those of apoptosis, angiogenesis, cellular proliferation, transforming growth factor- $\beta$ or androgen receptor expression, had any statistically significant change after saw palmetto herbal blend.

No serious adverse event was associated with saw palmetto herbal blend. A single episode of mild gastrointestinal upset involving cramps and diarrhea that may have been associated with treatment resolved spontaneously with continued use of the product. In each group 18 men were sexually active at baseline and only 1 had a decrease in ejaculatory volume that may have been due to therapy. No changes in libido or potency were reported. A panel of 26 standard blood tests revealed no changes from normal baseline values in either group (Appendix 2).

Microfocal prostate cancer was diagnosed at baseline in 4 men and at the 6-month biopsy in another 4, including 3 and 1 in the placebo and saw palmetto groups, respectively. All are being followed without definitive intervention. Invasive stage T1c prostate cancer was diagnosed at repeat biopsy in 1 man in each of the groups. One patient elected radiotherapy, while the other has not elected any definitive treatment to date. No histological change attributable to saw palmetto herbal blend was identified in any carcinoma tissue.

\section{DISCUSSION}

Plant based therapy is widely given in men with symptomatic $\mathrm{BPH}$ in western Europe, where physicians prescribe herbal products in the same manner as they prescribe drugs. For example, in Italy plant based products are prescribed 5 times more often than $\alpha$-blocking agents or finasteride and in Germany more than $90 \%$ of all medications prescribed for symptomatic BPH involve phytotherapy. ${ }^{3}$ In a large multicenter trial Carraro et al observed that a French brand of saw palmetto extract was as effective as finasteride for decreasing symptoms and increasing urinary flow. ${ }^{13}$ In a recent meta-analysis of controlled European trials of saw palmetto extract Wilt et al noted that the saw palmetto effect significantly exceeded that of placebo in regard to overall urinary symptoms, nocturia and the maximal urinary flow rate. ${ }^{2}$ Thus, the interest in saw palmetto extract is great and its use in the United States is increasing rapidly, ${ }^{14}$ although to our knowledge controlled studies have not been performed in this country.

Lowe and $\mathrm{Ku}$ evaluated the European trials of saw palmetto extract and identified a number of shortcomings in many, including too few subjects, a lack of rigid inclusion and/or exclusion criteria, short duration, absence of product standardization and failure to administer a validated symptom questionnaire. ${ }^{4}$ Furthermore, in many studies no placebo effect was noted, raising additional concern since placebo mediated improvement was noted in virtually all clinical trials of BPH pharmaceuticals. Thus, Lowe and $\mathrm{Ku}$ stated that the available data may suggest but do not clearly establish the efficacy of saw palmetto extract for symptomatic BPH. ${ }^{4} \mathrm{~A}$ similar conclusion was drawn by Wilt et al, whose meta-analysis included more than 2,900 patients in 18 European trials. ${ }^{2}$

The lack of a statistically significant clinical benefit of saw palmetto herbal blend over placebo in our relatively small study groups is not surprising. In the largest saw palmetto extract data set of the meta-analysis of Wilt et al mean symptom score improvement over placebo was 1.4 points on a 19 -point scale and uroflowmetry improved $1.9 \mathrm{cc}$ per second. ${ }^{2}$ It is possible that in a larger series or one with longer followup the clinical differences in our 2 groups would become more pronounced.

The most important finding of our study is the morphometric observation that saw palmetto herbal blend causes invo- 
TABLE 4. Effects of saw palmetto herbal blend in men with symptomatic BPH

\begin{tabular}{|c|c|c|c|c|c|c|}
\hline \multirow{2}{*}{ Mean $\pm \mathrm{SEM}$} & \multirow{2}{*}{ Baseline } & \multirow{2}{*}{ Randomization } & \multicolumn{4}{|c|}{ Treatment, Wk. } \\
\hline & & & 6 & 12 & 18 & 24 \\
\hline \multicolumn{7}{|l|}{ I-PSS: } \\
\hline Placebo & $16.35 \pm 1.12$ & $16.00 \pm 1.22$ & $14.61 \pm 1.48$ & $13.93 \pm 1.24$ & $13.87 \pm 1.23$ & $13.30 \pm 1.27$ \\
\hline Saw palmetto herbal blend & $18.43 \pm 1.47$ & $15.67 \pm 1.29$ & $13.43 \pm 1.52$ & $13.81 \pm 1.52$ & $12.62 \pm 1.55$ & $12.85 \pm 1.47$ \\
\hline \multicolumn{7}{|l|}{ Max. urine flow (cc/sec.) } \\
\hline Placebo & $11.22 \pm 0.98$ & $12.68 \pm 1.07$ & $12.77 \pm 1.19$ & $13.82 \pm 1.30$ & $13.27 \pm 1.28$ & $11.80 \pm 1.08$ \\
\hline Saw palmetto herbal blend & $10.47 \pm 0.95$ & $12.16 \pm 1.13$ & $13.43 \pm 1.31$ & $12.42 \pm 1.23$ & $10.64 \pm 0.99$ & $13.12 \pm 1.10$ \\
\hline \multicolumn{7}{|l|}{ Post-void residual urine vol. (cc): } \\
\hline Placebo & $72.24 \pm 15.10$ & $88.48 \pm 22.21$ & $58.87 \pm 11.98$ & $60.50 \pm 15.10$ & $92.48 \pm 19.23$ & $60.32 \pm 16.05$ \\
\hline Saw palmetto herbal blend & $90.75 \pm 19.95$ & $117.24 \pm 25.32$ & $88.05 \pm 18.84$ & $85.57 \pm 21.98$ & $100.95 \pm 27.53$ & $98.75 \pm 29.43$ \\
\hline \multicolumn{7}{|l|}{ Total serum PSA (ng./ml.): } \\
\hline Placebo & $4.06 \pm 0.73$ & & & $3.89 \pm 0.69$ & & $4.17 \pm 0.84$ \\
\hline Saw palmetto herbal blend & $2.67 \pm 0.43$ & & & $2.74 \pm 0.52$ & & $2.80 \pm 0.48$ \\
\hline \multicolumn{7}{|l|}{ Free serum PSA (ng./ml.): } \\
\hline Placebo & $0.99 \pm 0.24$ & & & $0.85 \pm 0.20$ & & $0.97 \pm 0.27$ \\
\hline Saw palmetto herbal blend & $0.60 \pm 0.08$ & & & $0.53 \pm 0.08$ & & $0.55 \pm 0.08$ \\
\hline \multicolumn{7}{|l|}{$\%$ Free PSA: } \\
\hline Placebo & $26.64 \pm 2.36$ & & & $22.27 \pm 1.82$ & & $22.51 \pm 1.75$ \\
\hline Saw palmetto herbal blend & $26.91 \pm 2.15$ & & & $23.21 \pm 1.79$ & & $22.65 \pm 2.01$ \\
\hline \multicolumn{7}{|l|}{ Testosterone (ng./dl.): } \\
\hline Placebo & $4.86 \pm 0.35$ & & & $4.60 \pm 0.45$ & & $4.47 \pm 0.40$ \\
\hline Saw palmetto herbal blend & $4.02 \pm 0.42$ & & & $4.52 \pm 0.36$ & & $4.31 \pm 0.46$ \\
\hline \multicolumn{7}{|l|}{ Dihydrotestosterone (ng./dl.): } \\
\hline Placebo & $0.60 \pm 0.10$ & & & $0.50 \pm 0.08$ & & $0.70 \pm 0.11$ \\
\hline Saw palmetto herbal blend & $0.66 \pm 0.06$ & & & $0.52 \pm 0.04$ & & $0.66 \pm 0.09$ \\
\hline \multicolumn{7}{|l|}{ Estradiol (pg./ml.): } \\
\hline Placebo & $20.04 \pm 1.59$ & & & $19.22 \pm 1.58$ & & $23.00 \pm 1.79$ \\
\hline Saw palmetto herbal blend & $19.52 \pm 1.70$ & & & $18.00 \pm 1.40$ & & $20.45 \pm 1.26$ \\
\hline \multicolumn{7}{|l|}{ Whole prostate vol. (cc): } \\
\hline Placebo & $55.65 \pm 5.56$ & & & & & $55.87 \pm 5.92$ \\
\hline Saw palmetto herbal blend & $58.49 \pm 6.51$ & & & & & $61.91 \pm 7.22$ \\
\hline \multicolumn{7}{|l|}{$\begin{array}{l}\text { Transition zone prostate vol. } \\
\text { (cc): }\end{array}$} \\
\hline Placebo & $27.37 \pm 4.57$ & & & & & $27.79 \pm 4.79$ \\
\hline Saw palmetto herbal blend & $32.22 \pm 6.32$ & & & & & $31.30 \pm 6.37$ \\
\hline
\end{tabular}

None of the effects was statistically significant.

lution of the prostatic epithelium in men with symptomatic $\mathrm{BPH}$. Modest support for our morphometric finding was provided by histological studies, which revealed a treatment associated increase in the rate of atrophy (fig. 2). The percent of atrophy was different at baseline in the 2 groups. This finding was probably a chance result of our small sample size but it limits the strength of this supporting evidence. Histological data suggest but do not conclusively confirm our morphometric finding of epithelial involution. Morphometrically, involution was especially pronounced in the transition zone, where epithelial composition decreased from $17.8 \%$ at baseline to $10.7 \%$ after 6 months of saw palmetto herbal blend ( $p$ $<0.01$ ). It is unclear how epithelial involution translates to clinical efficacy in the absence of prostate volume contraction.

The epithelial contraction associated with saw palmetto herbal blend appears similar to that after finasteride treatment. ${ }^{6}$ However, since saw palmetto treatment caused no decrease in serum PSA or prostate volume, the mechanism of action must be different. In fact, serum dihydrotestosterone did not decrease, indicating that the inhibition of 5- $\alpha$ reductase is not an important part of the mechanism (table 4). ${ }^{15-17}$ Since we noted no effect of saw palmetto herbal blend on prostate inflammatory tissues, we did not confirm the antiinflammatory hypothesis of Helpap et al. ${ }^{18}$

An unexplained finding in our series is the lack of a change in serum PSA despite marked epithelial contraction. This apparent paradox may involve some novel mechanism of action that was not detected in our studies of apoptosis, cell proliferation, growth factors, angiogenesis and androgen receptor expression. Our relatively small sample size may have caused skewing of the data in a way that obscured the true mechanisms. In this regard baseline atrophy data were different in the 2 groups, perhaps resulting from some degree of sampling error (fig. 4). Nevertheless, the involution of epithelial tissues confirmed by 2 independent and comple-

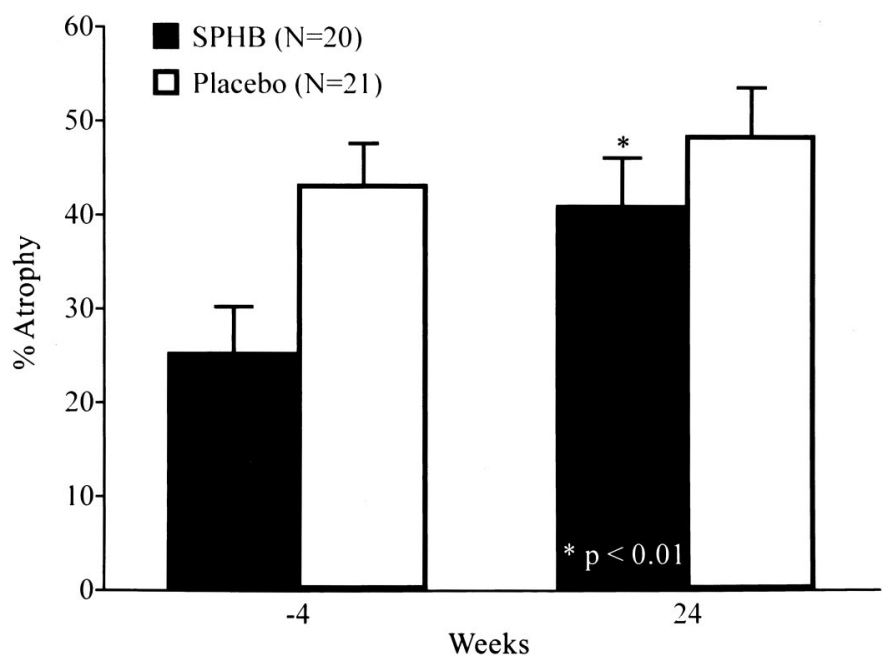

FIG. 2. Atrophy rate in whole prostate cores increased significantly in saw palmetto herbal blend $(S P H B)$ group from $25.2 \%$ at baseline to $40.9 \%$ at 6 months. Atrophy rate in placebo treated men did not change significantly from baseline. Baseline was different in each group.

mentary tests indicates that saw palmetto extract results in at least 1 measurable if currently unexplained effect on the human prostate. No change was noted in serum testosterone, dihydrotestosterone or estradiol, or in the prostate tissue expression of androgen receptors. In addition, sexual side effects were absent. Thus, the mechanism of action does not appear to be hormonal.

In our study saw palmetto intervention involved an herbal blend and not pure saw palmetto extract (table 3 ). Thus, these data may or may not apply to pure saw palmetto 

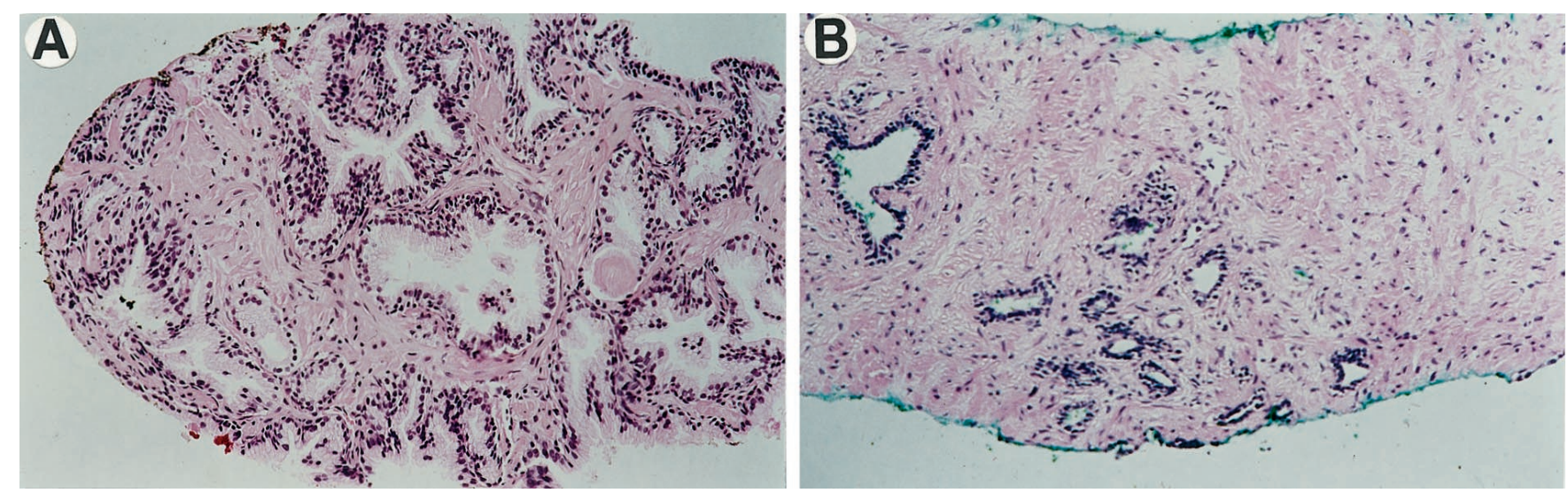

FIG. 3. Representative sample of epithelial involution. Reduced from $\times 300$. $A$, before saw palmetto herbal blend treatment. $B$, after 6 months of treatment epithelial cells flattened and acini diameter decreased.
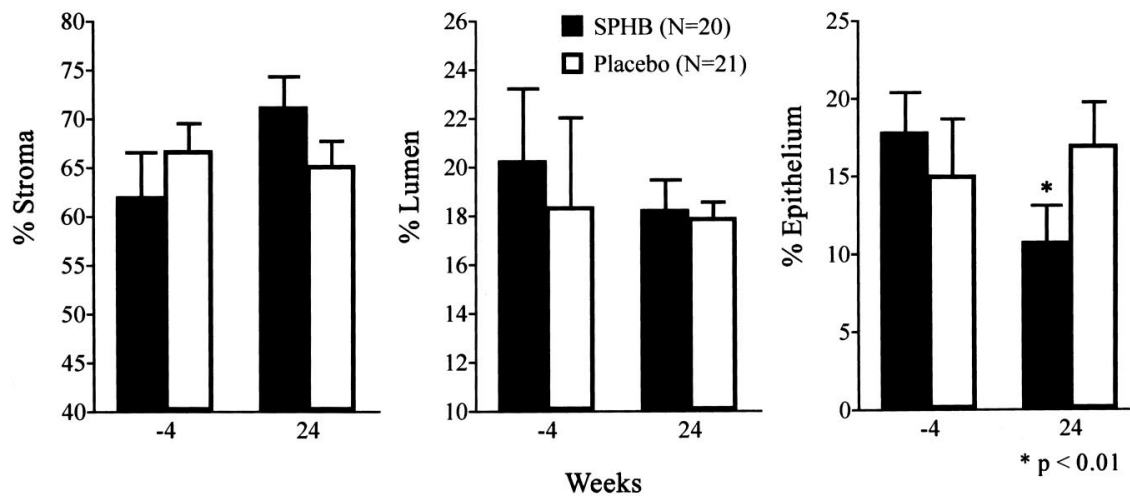

Fig. 4. Tissue composition of prostate transition zone. Epithelium decreased from $17.8 \%$ at baseline to $10.7 \%$ after 6 months of saw palmetto herbal blend $(S P H B)$ treatment. Increase was slight in placebo treated men. Luminal and stromal percents also decreased (not statistically significant).

extract products. We are unaware of convincing studies that support the efficacy of any other single ingredient used alone for treating symptomatic BPH. However, nettle root extract and pumpkin seed oil have a long history of use in European preparations, often in combination with saw palmetto extract, for the treatment of $\mathrm{BPH}$.

We noted no adverse effects of saw palmetto herbal blend therapy. Patient desire for saw palmetto herbal blend treatment was great, as evidenced by the nearly uniform enrollment of subjects in each group into the open label extension. The interest of men in herbal remedies with a prostate condition was reported by Gerber et al in a study of $\mathrm{BPH}^{19}$ and by Nam et al in a study of prostate cancer. ${ }^{20}$

Due to the pathophysiological effect in our series and clinical efficacy in the large study of Wilt et $\mathrm{al}^{2}$ the saw palmetto option deserves consideration as first line intervention in men with symptomatic and uncomplicated $\mathrm{BPH}$. However, current laws governing the manufacture and sale of herbal products in the United States do not protect consumers to the same extent as those governing pharmaceutical products. ${ }^{21-23}$ Hundreds of branded saw palmetto extract products are available. Thus, specific saw palmetto extract products as well as other phytotherapeutic substances should be evaluated within the medical mainstream and then, as appropriate, offered in perspective to the many patients who desire "safe, natural remedies."1

\section{CONCLUSIONS}

Saw palmetto herbal blend for symptomatic BPH resulted in the contraction of prostatic epithelial tissues, apparently via a nonhormonal mechanism. Serum PSA was unchanged. The effect on symptom score and urinary flow was mild but statistically significant in large studies. Thus, saw palmetto herbal blend appears to be a reasonable alternative for men with early, uncomplicated prostatism. No major side effects were observed.

Drs. Natasha Kyprianou, Gail Prins, Angela Ng and David Hess performed the tissue studies, Dr. Harry Rittenhouse donated the PSA kits and Debra Topham initiated the study. Saw palmetto extract capsules were provided and blinding was done by the Nutrilite Division of Amway Corp., Buena Park, California.

\section{APPENDIX 1: INCLUSION AND EXCLUSION CRITERIA}

Inclusion criteria

Patients must meet all of the following criteria at the screening visit.

Men age 45 to 80 years who are ambulatory, and in good general physical and mental health

Clinical diagnosis of $\mathrm{BPH}$ based on moderate to severe symptoms and palpation of an enlarged prostate gland on rectal examination at the screening visit

I-PSS questionnaire at the screening and baseline visits

Total patient score on the questionnaire must be 9 or more

Question 5 must have a numerical rating of 1 or more

Two of any of questions 1 to 4, 6 or 7 must have a numerical rating of 3 or more

PSA less than $15 \mathrm{ng} . / \mathrm{ml}$. at the screening visit with the serum sample for PSA drawn before the digital rectal examination and urinalysis

Prostate volume $30 \mathrm{cc}$ or more on transrectal ultrasound or MRI 
Patient ability to provide informed consent Exclusion criteria

Failure to meet the inclusion criteria

History of allergy to saw palmetto or to any component of the proprietary herbal blend

History of any illness or condition that in the opinion of the investigator may confound the results of the study or pose additional risk to the patient

Significant abnormalities on pre-study clinical examination or laboratory measurements

Treatment with any investigational drug during the previous month

Drug or alcohol abuse or dependence

Concurrent use of $\alpha$-adrenergic receptor antagonists (prazosin, terazosin, doxazosin or tamsulosin) and/or any hormonal therapy that may affect the prostate (for example gonadotropic releasing hormone agonists, testosterone antagonists or anabolic steroids), and use of finasteride or prostate phytotherapy within the last 18 months or $\alpha$-blockers within the last 1 month

Evidence of urethral stricture or radiotherapy to the pelvis

Diagnosis of chronic prostatitis or repeat urinary tract infection (3 or more episodes in the last year) or active urinary tract infection confirmed by a positive pre-study urine culture, although patients may enter the study after the successful resolution of an acute urinary tract infection

Previous bladder surgery, prostatectomy or another invasive procedure for $\mathrm{BPH}$, including transurethral incision of the prostate, balloon urethroplasty, microwave hyperthermia, urethral stenting and so forth

Known or suspected neurogenic bladder, such as severe diabetic neuropathy

History of recurrent acute urinary retention episodes

Patient inability to provide written informed consent for any reason, including legal incompetence, language or comprehension difficulty and psychological, psychiatric or emotional factors

Patient inability to undergo transrectal ultrasonography with biopsy for any reason

\section{APPENDIX 2: PANEL OF 26 STANDARD BLOOD TESTS}

\section{Hemoglobin}

Hematocrit

White blood count with differential

Platelet count

Iron

Iron binding capacity

Glucose

Blood urea nitrogen

Creatinine

Phosphorus

Uric acid

Total protein

Albumin

Globulin

Bilirubin

Alkaline phosphatase

Serum glutamic-oxaloacetic transaminase

Serum glutamate pyruvate transaminase

Aspartate transaminase

Lactate dehydrogenase

Sodium

Chloride

Magnesium

Potassium

Cholesterol

Triglycerides

\section{REFERENCES}

1. Marks, L. S. and Tyler, V. E.: Saw palmetto extract: newest (and oldest) treatment alternative for men with symptomatic benign prostatic hyperplasia. Urology, 53: 457, 1999

2. Wilt, T. J., Ishani, A., Stark, G. et al: Saw palmetto extracts for treatment of benign prostatic hyperplasia: a systematic review. JAMA, 280: 1604, 1998

3. Buck, A. C.: Phytotherapy for the prostate. Brit J Urol, 78: 325, 1996

4. Lowe, F. C. and Ku, J. C.: Phytotherapy in treatment of benign prostatic hyperplasia: a critical review. Urology, 48: 12, 1996

5. Lowe, F. C. and Fagelman, E.: Phytotherapy in the treatment of benign prostatic hyperplasia: an update. Urology, 53: 671, 1999

6. Marks, L. S., Partin, A. W., Gormley, G. J. et al: Prostate tissue composition and response to finasteride in men with symptomatic benign prostatic hyperplasia. J Urol, 157: 2171, 1997

7. Marks, L. S., Partin, A. W., Dorey, F. J. et al: Long-term effects of finasteride on prostate tissue composition. Urology, 53: 574, 1999

8. Hodge, K. K., McNeal, J. E., Terris, M. K. et al: Random systematic versus directed ultrasound guided transrectal core biopsies of the prostate. J Urol, 142: 71, 1989

9. Kyprianou, N., Litvak, J. P., Borkowski, A. et al: Induction of prostate apoptosis by doxazosin in benign prostatic hyperplasia. J Urol, 159: 1810, 1998

10. Bostwick, D. G., Wheeler, T. M., Blute, M. et al: Optimized microvessel density analysis improves prediction of cancer stage from prostate needle biopsies. Urology, 48: 47, 1996

11. Perry, K. T., Anthony C. T. and Steiner, M. S.: Immunohistochemical localization of TGF beta 1 , TGF beta 2 , and TGF beta 3 in normal and malignant human prostate. Prostate, 33: 133, 1997

12. Prins, G. S., Sklarew, R. J. and Pertschuk, L. P.: Image analysis of androgen receptor immunostaining in prostate cancer accurately predicts response to hormonal therapy. J Urol, 159: 641, 1998

13. Carraro, J.-C., Raynaud, J.-P., Koch, G. et al: Comparison of phytotherapy (Permixon) with finasteride in the treatment of benign prostate hyperplasia: a randomized international study of 1098 patients. Prostate, 29: 231, 1996

14. Eisenberg, D. M., Davis, R. B., Ettner, S. L. et al: Trends in alternative medicine use in the United States, 1990-1997: results of a follow-up national survey. JAMA, 280: 1569, 1998

15. Rhodes, L., Primka, R. L., Berman, C. et al: Comparison of finasteride (Proscar), a 5 alpha reductase inhibitor, and various commercial plant extracts in in vitro and in vivo 5 alpha reductase inhibition. Prostate, 22: 43, 1993

16. Strauch, G., Perles, P., Vergult, G. et al: Comparison of finasteride (Proscar) and Serenoa repens (Permixon) in the inhibition of 5-alpha reductase in healthy male volunteers. Eur Urol, 26: 247,1994

17. Weisser, H., Behnke, B., Helpap, B. et al: Enzyme activities in tissue of human benign prostatic hyperplasia after three months' treatment with the Sabal serrulata extract IDS 89 (Strogen) or placebo. Eur Urol, 31: 97, 1997

18. Helpap, B., Oehler, U., Weisser, H. et al: Morphology of benign prostatic hyperplasia after treatment with Sabal extract IDS 89 or placebo J Urol Pathol, 3: 175, 1995

19. Gerber, G. S., Bales, G., Kirsh, E. et al: Medicinal botanicals in the treatment of lower urinary tract symptoms (LUTS): a demographic analysis of awareness and use at the University of Chicago. J Urol, suppl., 159: 334, abstract 1282, 1998

20. Nam, R. K., Fleshner, N., Rakovitch, E. et al: Prevalence and patterns of the use of complementary therapies among prostate cancer patients: an epidemiological analysis. J Urol, 161: 1521,1999

21. Angell, M. and Kassirer, J. P.: Alternative medicine-the risks of untested and unregulated remedies. N Engl J Med, 339: 839, 1998

22. Dietary Supplement Health and Education Act of 1994. Public Law 103-417.

23. Slifman, N. R., Obermeyer, W. R., Aloi, B. K. et al: Contamination of botanical dietary supplements by Digitalis lanata. N Engl J Med, 339: 806, 1998 